\title{
DENTAL ANOMALY IN TAPIRUS TERRESTRIS (L.)
}

\author{
by \\ D. A. HOOIJER \\ Rijksmuseum van Natuurlijke Historie, Leiden
}

A male skull of Tapirus terrestris (L.) originating from Dutch Guiana (Leiden Museum, reg. no. 11632), received from the Rotterdam Zoological Garden through the kind intermediary of Mr. F. J. APPELMAN on July 15,1952 , is remarkable for the abnormal development of its right $\mathbf{P}$. The full permanent dentition is in place except for the posterior premolars and last molars, which are in alveolo. The teeth are but little worn and, apart from the right $\mathbf{P}^{\mathbf{1}}$, they do not show any unusual characters.

The left $\mathrm{P}^{1}$ has the shape normally found in the Brazilian tapir; the crown is triangular with rounded angles, and bears a continuous outer crest (ectoloph) extending from the front angle (parastyle) to the posterior outer cusp (metacone). The position of the central outer cusp (paracone), merged in the crest, is indicated only by a weak vertical ridge on the labial face of the ectoloph, flattening toward the crown base, the paracone style. The posterior inner cusp (hypocone) is a low but distinct, anteroposteriorly elongated elevation of the cingulum. The protocone is just visible as a tiny cusp on the lingual cingulum, internal to the paracone. The labial cingulum is shown as a slight swelling all along the base of the ectoloph. There is a broad posterior root, imperfectly subdivided into a larger labial and a smaller lingual portion, and there is a single anterior root; the roots are but slightly divergent. The anteroposterior diameter of the crown is $17.1 \mathrm{~mm}$, the posterior width, $13.2 \mathrm{~mm}$.

The right $\mathrm{P}^{1}$ is shorter anteroposteriorly $(14.8 \mathrm{~mm})$ by the same width $(13.2 \mathrm{~mm})$, and is very different in structure from its fellow on the left side of the skull. The paracone stands as a large isolated cone in the centre of the crown, distinctly separated from the slightly lower metacone posterior to it, and from the parastyle, a mere cingular elevation in front. The hypocone is marked off from the metacone by a cleft but is very similar in development to that in the left $P^{1}$, as will be seen in the photographs. There is no trace of a protocone. The labial margin of the crown is convex instead of flattened, and it bears a prominent cingulum. The posterior root is as broad as that in the left $\mathrm{P}^{1}$ but more distinctly subdivided, while the anterior root is much weaker, and diverges more from the posterior root. There is a nodule on the base of the crown, between the anterior and the posterior root, not seen in the normal $\mathbf{P}^{1}$.

Thus, the major feature of the right $\mathrm{P}^{1}$ is the absence of the connecting ridge between metacone and parastyle, the ectoloph, which is such a prominent feature in a normal $\mathrm{P}^{1}$ of Tapirus.

Ridges are less stable than the cusps which they join (BuTLER, 1956, p. 52). As an illustration of this among perissodactyl premolars I may refer to the variations in the connection of the protocone with the hypocone in $\mathrm{P}^{2}$ of Trigonias osborni Lucas, joined on one side of the skull, separate on the other (BUTLER, 1952 b, p. 833, fig. 71 ); the same variation exists in $\mathrm{DM}^{1}$ of the same species (BuTLER, 1952a, p. 789, fig. $6 \mathrm{~T}$ and $\mathrm{T}^{\prime}$ ) as well as of Ceratotherium simum (Burchell), recent (ButLer, 1952a, p. 789) and fossil (Hoorjer, 1959, p. 5, fig $1 \mathrm{C}$ and E). The protoloph and the metaloph show a wide range of variation in the upper premolars of Trigonias (GREGorY and Cook, 1928, figs. 4-5), but not so the ectoloph, which is complete in all the specimens figured. The ectoloph is a more stable structure than any of the other ridges in upper premolars and milk molars of perissodactyls. The only instance of an incomplete ectoloph in a rhinoceros seen by me is in a $\mathrm{DM}^{2}$ of Merck's rhinoceros, Dicerorhinus merckii (Jäger), from the Upper Pleistocene rock shelter of Ksâr'Akil, Lebanon, which shows a deep cleft in the ectoloph just in front of the mesostyle. This is a definite anomaly, and a very rare one at that. 
In the case of the $\mathrm{P}^{\mathbf{1}}$ of Tapirus terrestris discussed above the whole of the ectoloph has failed to develop: there are only the three cusps of the parastyle, paracone, and metacone, as in the primitive bunodont stage before any lophs had yet evolved. Is it possible to give some interpretation of the absence of this ridge in the light of what is known about the ontogeny of teeth?

"Ridges are probably produced by tensions set up in the epithelium by the relative movement of the cusps, owing to unequal growth or to changes in the shape of the follicle. They form in areas where growth has slowed down but the apposition of hard tissues has not begun" (BUTLER, 1956, p. 60/61). I am grateful to Dr. P. M. ButLen for pointing out to me that an anomaly such as that dealt with in the present note suggests continued growth of the areas between the cusps. This may have had the effect of eliminating any ridge formation by forcing the epithelium down toward the base of the crown. As a matter of fact the anomalous right $P^{1}$ has a deep cleft between paracone and metacone, and such a cleft is also seen between metacone and hypocone, where the normal $P_{1}$ has only a shallow valley. The intensified crown relief of the anomalous tooth resulted from continued growth in the valleys.

There remains to be mentioned that the right $\mathbf{P}_{1}$ occludes with its antagonist in the normal way; the paracone has a small facet lingually, and touches the labial face of the metalophid between paraconid and protoconid just as does the ectoloph of the left $\mathbf{P}^{\mathbf{1}}$.

\section{REFERENCES}

Butler, P. M., 1952a: The milk-molars of Perissodactyla, with remarks on molar occlusion. Proc. Zool. Soc. London, vol. 121, pp. 777-817, 16 figs.

ButLen, P. M., 1952b: Molarization of the premolars in the Perissodactyla. Ibid., vol. 121, pp. 819-843, 93 figs.

Butler, P. M., 1956: The ontogeny of molar pattern. Biol. Reviews, vol. 31, pp. 30-70, 12 figs.
Grecony, W. K. and H. J. Coox, 1928: New material for the study of evolution. A series of primitive rhinoceros skulls (Trigonias) from the Lower Oligocene bf Colorado. Proc. Colo. Mus. Nat. Hist., vol. 8, pp. 1-32, 6 pls., 5 figs.

Hoorjer, D. A., 1959; Fossil rhinoceroses from the Limeworks Cave, Makapansgat. Pal. Africana, vol. 6, pp. 1-13, 4 figs. 


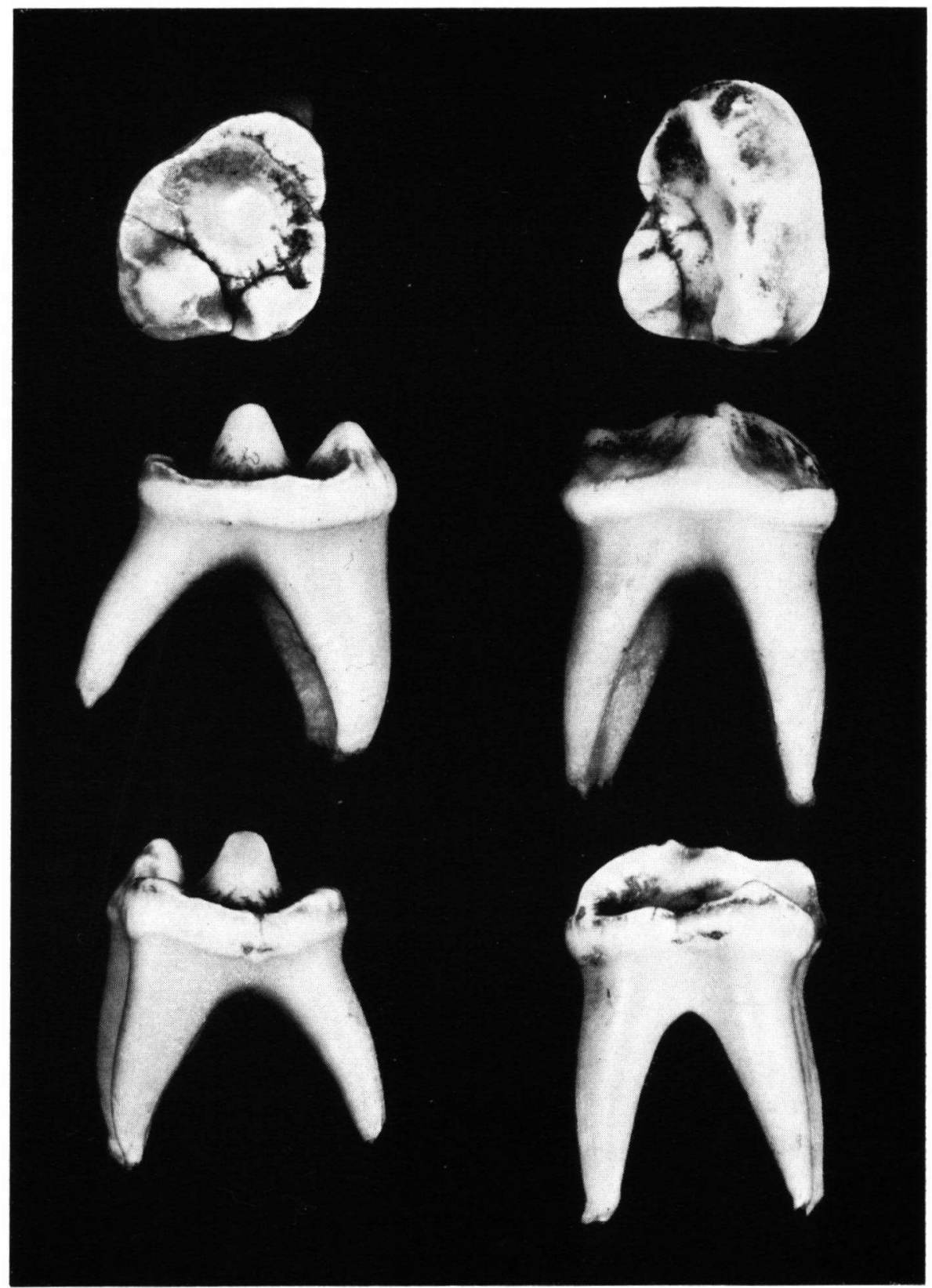

$\mathrm{P}^{1}$ dext. and $\mathrm{P}^{1}$ sin. of Tapirus terrestris (L.) from Dutch Guiana (Leiden Museum, reg. no. 11632). Left: the anomalous $P^{1}$ dext. Right: the normal $P^{1}$ sin. Top: crown views. Middle: outer views. Bottom: inner views. All figures twice natural size. 